\title{
Predicted Steady State Volume of Distribution
}

National Cancer Institute

\section{Source}

National Cancer Institute. Predicted Steady State Volume of Distribution. NCI Thesaurus. Code C85794.

An estimate of the volume of distribution at steady state, which is the mean residence time (MRT) extrapolated to infinity times steady state clearance (MRTINF*Clss), based on the predicted last concentration. 